\title{
Environmental influences on male reproduction
}

\author{
R.F.A. WEBER*, F.H. PIERIK*†, G.R. DOHLE* and A. BURDORF $\dagger$ \\ *Department of Andrology, and tDepartment of Public Health, Erasmus University Medical Centre, Rotterdam, the Netherlands
}

\section{Summary}

Considerable concern has been raised in recent publications that oestrogen-like compounds in either food or the environment cause adverse effects on reproductive health. There is clear evidence that reproductive disruption in wildlife may be caused by environmental pollutants and more specifically by endocrine-disrupting compounds. The increase in the incidence of disorders of the male reproductive tract (e.g. testicular cancer, cryptorchidism, hypospadias) and the possible decline of sperm quality led to the hypothesis in 1993 that the reported increases stem from fetal or neonatal exposure of the developing male to oestrogens. Cryptorchidism, hypospadias, testicular cancer and poor semen quality have also been proposed to be symptoms of one underlying cause, the testicular dysgenesis syndrome, which may develop during fetal life under the influence of environmental factors. However, there is only circumstantial evidence in humans that exposure to endocrine disrupters, especially diethylstilbestrol, during pregnancy causes problems of reproductive health. Oestrogen-like effects have been reported for a variety of naturally occurring oestrogens (so-called phytoestrogens) and for numerous synthetic compounds. The critical issue is whether there are sufficiently high levels of endocrine disrupters in the ambient environment to exert adverse health effects on the general population.

\section{Introduction}

Reproductive functions in most species are under the control of the endocrine system. Colborn [1] described in detail the possible threat from environmental pseudooestrogens on reproductive function in wildlife, e.g. the small penises of alligators in Lake Apopka, Florida, decreasing sperm quality in panthers, the decreasing number of bald eagles, behavioural changes in seagulls (e.g. supranormal clutch size and female-female pairing) and pseudo-hermaphroditism in fish. Chemicals in the environment that mimic or block endogenous hormones might disturb the fine balance of the endocrine system [2]. The potential implications for human health and for numerous other species are obvious. Endocrine disruption is thus of growing public health and environmental concern. From the perspective of human pathology, the environmental endocrine hypothesis might be the most significant environmental health hypothesis. Much of the emphasis of research has been on changes in male reproductive health.

The incidence of testicular cancer has increased in almost all countries which have reliable cancer registers. There is circumstantial evidence for a decline in sperm counts, and there are indications that the incidence of cryptorchidism and hypospadias is increasing.

There is controversy about whether oestrogens in the environment would cause significant male reproductive disorders. Exposure to endocrine-disrupting compounds is almost entirely through the diet, particularly milk and other dairy products, fish and meat, and fruit and vegetables. Furthermore, there is industrial exposure to, e.g. dioxins in workers producing phenoxy herbicides and chlorophenols, in subjects exposed in the industrial accident in Seveso and in subjects exposed during herbicide application [3].

\section{Hypothesis}

The increasing incidence of reproductive abnormalities in the male may be related to increased oestrogen exposure in utero [4], disrupting the development of the testis and the rest of the male reproductive tract (Fig. 1). Regression of the Müllerian ducts, and the development and descent of the testes into the scrotum occur during fetal life. Increased exposure to oestrogens may suppress FSH secretion by the fetal pituitary gland, which subsequently reduces the multiplication of Sertoli cells and the secretion of Müllerian inhibiting substance (MIS), which causes regression of the Müllerian ducts. Persistence of these ducts is usually associated with impaired testicular descent (cryptorchidism). MIS may also be responsible for suppressing the multiplication of germ cells during fetal life. Masculinization of the male reproductive tract, via effects on the Wolffian ducts and external genitalia, and the second phase of testicular descent is achieved by testosterone production in the Leydig cells. Exposure to oestrogen could also compromise testosterone production, leading to hypospadias. Thus abnormal 

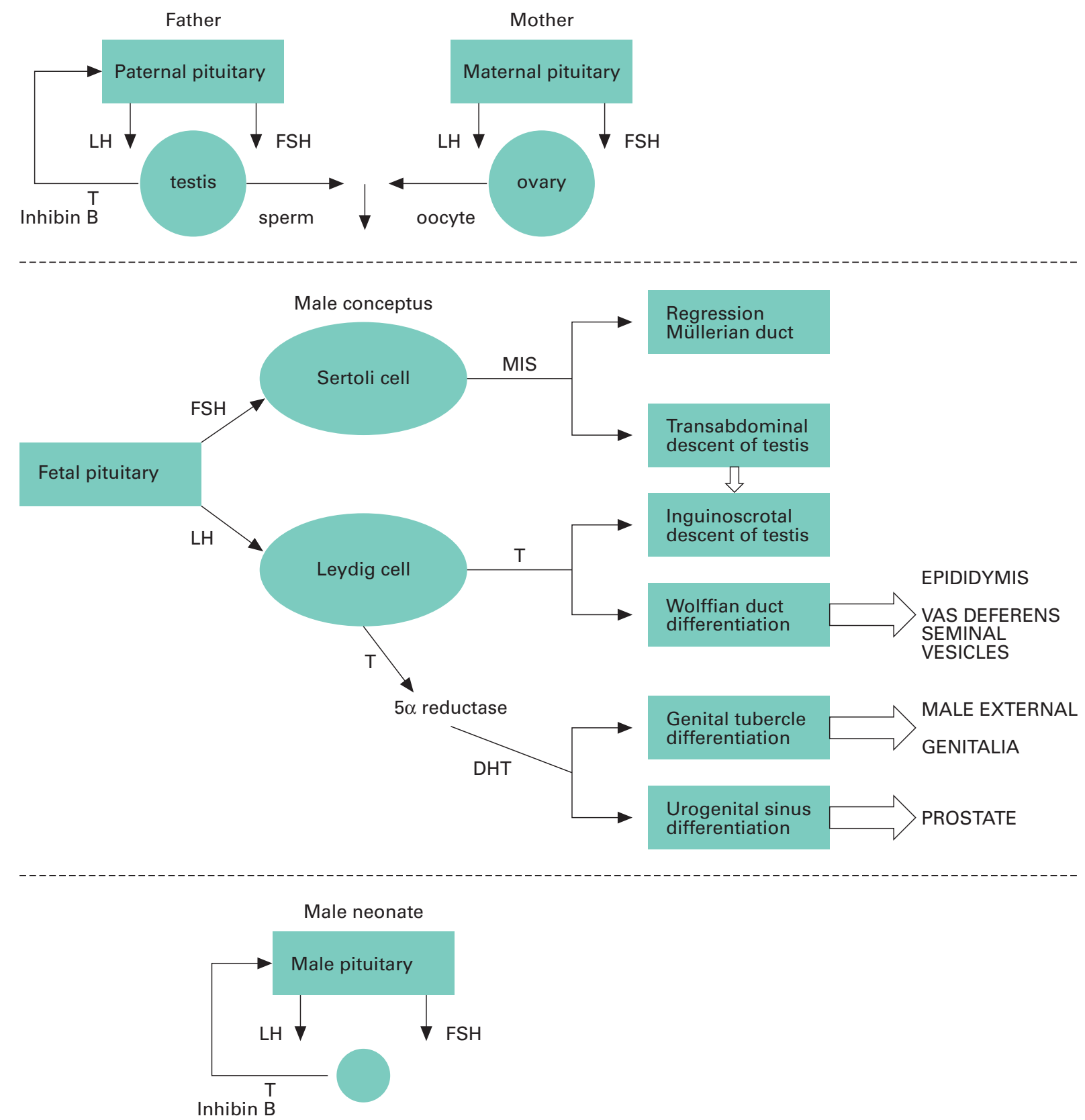

Fig. 1. A schematic representation of male reproductive function and development. $\mathrm{T}=$ testosterone.

development of the Sertoli and germ cells may lead to abnormal sperm production and/or infertility. The latter findings may also be caused by cryptorchidism itself.

Recently, it was proposed that poor semen quality, cryptorchidism, hypospadias and testicular cancer are symptoms of one underlying entity, the testicular dysgenesis syndrome (TDS) [5]. TDS may be caused by genetic or environmental factors, or both. Even though clinically the symptoms appear postnatally, the cause might be irreversible testicular dysgenesis during early fetal development. TDS may arise through disturbed Sertoli cell function, causing impaired germ cell differentiation and eventually reduced semen quality, carcinoma in situ and testicular cancer. TDS is also accompanied by decreased Leydig cell function, causing androgen insufficiency, and leading to hypospadias and cryptorchidism. Skakkebæk et al. [4] proposed that the presence of symptoms may vary with the severity of the syndrome.

Despite this hypothesis it is apparent that, as depicted in Fig. 1, adults of both sexes are also affected by 
endocrine disrupters [6]. Much of the knowledge of the action of endocrine disrupters in adult humans is derived from the use of various steroids as pharmacological agents.

\section{Endocrine disrupters}

In recent years there has been increasing concern about the potential of substances in the environment to disrupt endocrine systems in humans and wildlife. The primary emphasis to date has been on substances which might mimic oestrogen activity and can interfere with the normal functioning of the endocrine system.

The list of chemicals that are known to affect reproduction in humans via endocrine mechanisms include pesticides (DDT and its metabolites), polychlorinated biphenyls, dioxins, naturally occurring plant oestrogens (phytoestrogens), and mycotoxins. Several other chemicals (e.g. alkylphenols, phthalates and bisphenol A) have been shown to interfere with some endocrine-mediated processes, but evidence for effects on reproductive functions in vivo is lacking. Current methods for assessing human and wildlife health effects are generally targeted at detecting effects rather than mechanisms, and may not adequately evaluate effects on the endocrine system.

\section{Hypospadias}

There is some evidence for an increase in hypospadias rates during the last few decades [6,7]. Several explanations have been proposed, including increased exposure to endocrine disrupters during fetal life [4]. As published hypospadias rates are exclusively derived from birthdefect registries, artefacts in case ascertainment in these registers may account for the reported changes over time. The existing registries rely on the completeness of detection and reporting by doctors. Differences in case ascertainment may introduce variations in reported hypospadias rates, but the extent of confounding by these differences is unknown. Moreover, assumptions are made about the number of reference subjects, who are not all examined for the anomaly. Hospital registry data have been shown to be unreliable [5].

Dolk [8] recently discussed the possibility that the rise in hypospadias is caused by an increasing tendency to report minor hypospadias. This hypothesis is difficult to prove, as very few studies report the total distribution of cases by severity. As an example, the often cited increase in hypospadias rates in the USA is hampered by the lack of information on severity in most cases $(63 \%)$ [6]. As shown in Fig. 1, the development of male external genitalia depends on normal androgen action. Defects in the production of DHT or androgen insensitivity result in hypospadias.

\section{Cryptorchidism}

There are also indications that cryptorchidism may have increased in incidence in several countries [9] but in general cryptorchidism is registered more unreliably than is hypospadias. The reported values are $4-42$ per 10000 births. In England, the incidence of cryptorchidism increased by $>60 \%$ between the 1950s and 1980s. Also, this anomaly is regarded as being associated with exposure to endocrine disrupters in utero.

Transinguinal descent of the testes also depends on androgens [10] but disrupted androgen action can only explain a very small proportion of cases with cryptorchidism. In mice it has been shown that the formation of the gubernaculum, which is necessary for testicular descent, depends on insulin-like factor 3 (Insl 3) and its deletion causes cryptorchidism [11].

In male mice, fetal exposure to $17 \alpha$-ethinyl oestradiol (17-EE) results in an increased incidence of cryptorchidism [12], azoospermia, atrophy of seminiferous tubules, and altered Sertoli and Leydig cell differentiation [13]. In all these studies the mothers were exposed to high concentrations of 17-EE. Recently, the administration of very low doses prenatally to mice resulted in an increased prostate weight by 5 months of age and reduced daily sperm production during adolescence [14]. However, other studies were unable to repeat the finding of an increased prostate weight. Neonatal exposure to DES in male rats caused major developmental abnormalities of the testis, epididymis, vas deferens, seminal vesicles and prostate, when evaluated at the time of normal onset of puberty [15].

\section{Testicular cancer}

The most convincing evidence for a general decline in male reproductive health in humans is the increase in testicular cancer noted in the recent past in several Western countries [16-19]. Both cryptorchidism and hypospadias are associated with an increased risk of testicular cancer, based on the observation that men with cryptorchidism and/or hypospadias are over-represented among patients with testicular cancer.

The hypothesis that endocrine disruption can cause cancer in humans is based on the association between DES exposure of pregnant women and clear cell adenocarcinoma of the vagina and cervix in their female offspring. Some of the male offspring of women who took DES show pseudohermaphroditism [20] and genital malformations, including epididymal cysts, small 
testes, microphallus and reduced semen quality [21-23]. Follow-up surveys of DES-exposed male offspring have shown no impairment in fertility or sexual function $[24,25]$, or evidence of an increased risk of testicular cancer [24]. Dysgenic testes have a very high risk of developing testicular cancer in adulthood; these cancers seem to arise from premalignant gonocytes or carcinoma in situ cells.

\section{Declining sperm quality}

The possible decline in human semen quality has become a major issue of concern within the last decade. The decline in sperm count and/or sperm concentration, decrease of sperm motility and an increase in morphologically abnormal cells have been described as major factors for defining the impairment of semen quality. There is good evidence for positive associations between semen characteristics and the likelihood of achieving a pregnancy. However, the possible decline in semen quality has not yet resulted in reports of any reduction in male fertility. Moreover, as shown in Fig. 2, the outcome of the different studies is not unequivocally a decrease in sperm [26-40]. This makes it even more difficult to find a cause/effect relationship between decreasing sperm quality and the hypothesized exposure of pregnant women and their male offspring to hormone disrupters, and especially environmental oestrogens. The most commonly used variables in the various reports are sperm concentration (equivalent to sperm density, millions $/ \mathrm{mL}$ ), and total sperm count per ejaculate (millions/ejaculate).

The assessment of sperm morphology has changed over the years; currently $>70 \%$ of the spermatozoa have to be abnormal for the indication 'teratozoospermia' (abnormal morphology), but even this value has been considered to be too low. Some laboratories consider samples with $86 \%$ abnormal spermatozoa to be "normal'. The cause for the rapid lowering of the threshold value of 'normal-abnormal' is not the deterioration of sperm quality, but the method of evaluating sperm morphology. Moreover, even the WHO manual for examining human semen and semen-cervical mucus interaction gives no unequivocal description of normal morphology.

The variability in a man's semen characteristics may be considerable, possibly through several factors, e.g. the period of abstinence, recent and present disease, use of certain medication, drug and alcohol abuse, and the circumstances under which the sample is produced [41]. In addition to the well-known fluctuations of semen quality, the methods of assessment also have many limitations and inherent errors. These inadequacies are augmented by the different methods still being used to count sperm cells. Although the WHO has made recommendations to standardize the procedures for analysing human sperm, these have not been generally applied. In an external quality-control programme, the semen analysis showed wide between-laboratory variation in both the sperm concentration and morphology assessments.

The comparability of publications reporting declining sperm quality is limited because they comprise different populations (infertile men, sperm donors with or without known fertility, and men cryopreserving sperm before vasectomy) in different countries. None of these populations can be regarded as representative of the normal population.

Also, there are many complicating factors, most of which are not addressed in studies on sperm quality (Table 1), but that can have an effect on sperm quality. Some of these factors may even be considered as 'environmental'.

Various illnesses may affect semen characteristics; fever can even lead to azoospermia. A moderate increase in the scrotal temperature may have deleterious effects on spermatogenesis, leading to severe decreases in sperm concentration. The increase in scrotal temperature caused by wearing tight underwear, taking hot baths or a sauna has been associated with a decrease in sperm concentration [42]. The presence of a varicocele may lead to an impairment of scrotal temperature regulation. Whilst cooling of the scrotum is normally best when a man is walking or standing, in men with a varicocele the scrotal temperature is increased in these conditions.

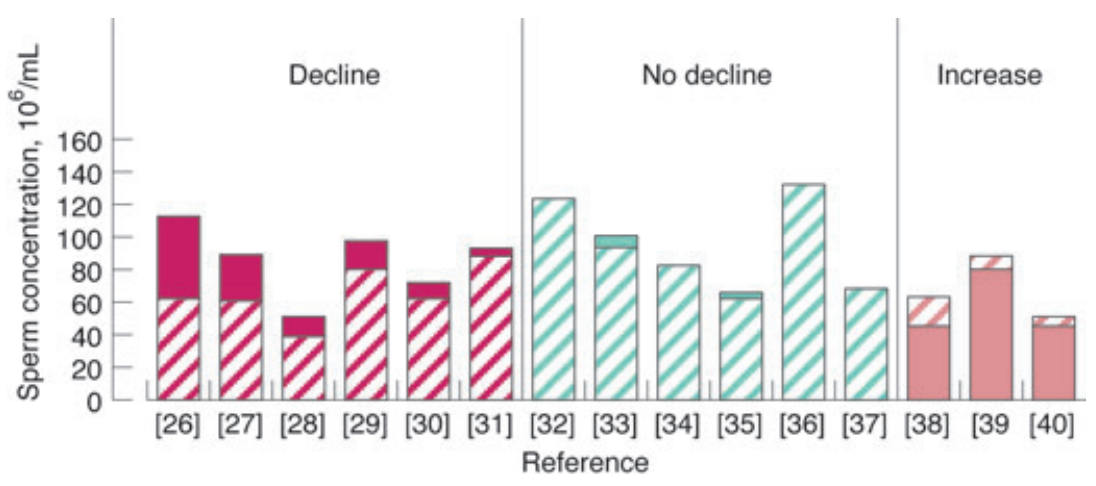

Fig. 2. Studies on sperm concentration published since 1992. The hatched areas show sperm concentration after decline, no decline and increase, respectively. 
Table 1 A summary of factors that may affect sperm quality

\begin{tabular}{l} 
Factor/Details \\
Methodology of sperm analysis \\
Lack of standardization of sperm collection \\
Lack of standardization of laboratory procedures \\
Complicating factors \\
Season of sampling \\
Lifestyle \\
Profession \\
Diseases \\
Medication \\
Stress \\
Age \\
Trends \\
Higher prevalence of varicoceles associated with \\
increased body height \\
Changes in lifestyle \\
Environmental changes \\
Changes in occupational activities \\
Fluctuations over the year \\
Seasonal changes \\
Influence of geography \\
Ethnicity \\
Fertility status \\
Influence of study population \\
Changes in composition of the population visiting \\
fertility (related) clinics \\
Region of habitation \\
\hline
\end{tabular}

Some therapeutic drugs, e.g. sulphasalazine and cytostatic drugs, are known to have direct side-effects causing infertility. Smoking, alcohol abuse, drug abuse (anabolics), and both physical (especially endurance training) and psychological stress have a negative effect on spermatogenesis. Acute stress resulting from an earthquake reduced sperm concentration and motility in one study.

\section{Geographical differences in sperm quality}

The sperm count may vary among different geographical locations. Variations in sperm counts have been described between different states in the USA (with values from New York being the highest [43]) and in Europe [44,45]. A meta-analysis of 61 studies [26] created considerable debate. The question that remains unanswered is whether data on sperm quality may be analysed and compared, in view of the numerous complicating factors that contribute to sperm quality. There is doubt whether the decline in sperm quality can be explained by environmental factors. Indeed, environmental exposure to endocrine disrupters has increased over the last decades, but it is impossible to conclude that a decline in sperm concentration, if any, can be attributed to environmental factors.

\section{Policy}

In 1996 the USA Environmental Protection Agency identified endocrine disruption as an environmental health problem. In 1999 the European Commission began the implementation of the Community strategy for endocrine disrupters. During 2000, a candidate list of 553 man-made substances and nine synthetic/natural hormones were identified. The Commission and Member States continue to participate in the Endocrine Disrupter Testing and Assessment Task Force, which was set up in 1998 with the goal of developing agreed test methods for endocrine disrupters.

\section{References}

1 Colborn Th, Dumanoski D, Peterson Meyers J. Our Stolen Future. Are We Threatening Our Fertility, Intelligence, and Survival? A Scientific Detective Story. New York and Baltimore: Dutton Books, 2000

2 Kogevinas M. Human health effects of dioxins: cancer, reproductive and endocrine system effects. Human Reprod Update 2001; 7: 331-9

3 Sharpe RM, Skakkebæk NS. Are oestrogens involved in falling sperm counts and disorders of the male reproductive tract? Lancet 1993; 341: 1392-5

4 Skakkebæk NS, Rajpert-De Meyts E, Main KM. Testicular dysgenesis syndrome; an increasingly common developmental disorder with environmental aspects. Human Reprod 2001; 16: 972-8

5 Toppari J, Kaleva M, Virtanen HE. Trends in the incidence of cryptorchidism and hypospadias, and methodological limitations of registry-based data. Human Reprod Update 2001; 7: 282-6

6 Paulozzi LJ, Erickson JD, Jackson RJ. Hypospadias trends in two US surveillance systems. Pediatrics 1997; 100: 831-4

7 Aho M, Koivisto A-M, Tammela TLJ, Auvinene A. Is the incidence of hypospadias increasing? Analysis of Finnish hospital discharge data 1970-94. Environ Health Perspect 2000; 108: 463-5

8 Dolk H. Rise in prevalence of hypospadias. Lancet 1998; 351: 770

9 Hutson JM, Hasthorpe S, Heyns CF. Anatomical and functional aspects of testicular descent and cryptorchidism. Endocr Rev 1997; 18: 259-80

10 Nef S, Parada LF. Cryptorchidism in mice mutant for Insl3. Nature Genet 1999; 22: 295-9

11 Zimmerman S, Steding G, Emmen JM et al. Targeted disruption of the Insl3 gene causes bilateral cryptorchidism. Mol Endocrinol 1999; 13: 681-91

12 Walker AH, Bernstein L, Warren DW, Warner NE, Zheng X, Henderson BE. The effect of in utero ethinyl oestradiol exposure on the risk of cryptorchid testis and testicular teratoma in mice. Br J Cancer 1990; 62: 599-602

13 Yasuda Y, Ohara I, Konishi H, Tanimura T. Long-term effects on male reproductive organs of prenatal exposure to ethinyl estradiol. Am J Obstet Gynecol 1988; 159: 1246-50 
14 Thayer KA, Ruhlen RL, Howdeshell KL et al. Altered prostate growth and daily sperm production in male mice exposed prenatally to subclinical doses of $17 \alpha$-ethinyl oestradiol. Human Reprod 2001; 16: 988-96

15 Williams K, McKinnell C, Saunders PTK et al. Neonatal exposure to potent and environmental oestrogens and abnormalities of the male reproductive system in the rat: evidence for importance of the androgen-oestrogen balance and assessment of the relevance to man. Human Reprod Update 2001; 7: 236-47

16 Adami H, Bergström R, Möhner M et al. Testicular cancer in nine northern European countries. Int J Cancer 1994; 59: $33-8$

17 Forman D, Møller H. Testicular cancer. Cancer Surv 1994; 19/20: 323-41

18 Møller H. Trends in sex-ratio, testicular cancer and male reproductive hazards: are they connected? APMIS 1998; 106: 232-9

19 Møller H. Trends in incidence of testicular cancer and prostate cancer in Denmark. Human Reprod Update 2001; 16: $1007-11$

20 Kaplan NM. Male pseudohermaphroditism. report of a case with observations on pathogenesis. N Engl J Med 1959; 261: 641-4

21 Gill WH, Schumacher FB, Bibbo M, Straus FH, Schoenberg HW. Association of diethylstilbestrol exposure in utero with cryptorchidism, testicular hypoplasia and semen abnormalities. J Urol 1979; 122: 36-9

22 Driscoll SG, Taylor SH. Effects of prenatal estrogen on the male urogenital system. Obstet Gynecol 1980; 56: 537-42

23 Stillman RJ. In utero exposure to diethylstilbestrol. Adverse effects on the reproductive tract and reproductive performance in male and female offspring. Am J Obstet Gynecol 1982; 142: 905-21

24 Leary FJ, Resseguie LHJ, Kurland LT, O'Brien PC, Ernslander RF, Noller KL. Males exposed in utero to diethylstilbestrol. JAMA 1984; 252: 2984-9

25 Wilcox AJ, Baird DD, Weinberg CR, Hornsby PP, Herbst AL. Fertility in men exposed prenatally to diethylstilbestrol. N Engl J Med 1995; 332: 1411-6

26 Carlsen E, Giwercman A, Skakkebaek N. Evidence for decreasing quality of semen during the past 50 years. Br Med J 1992; 305: 609-13

27 Auger J, Kunstmann JM, Czyglik F, Jouannet P. Decline in semen quality among fertile men in Paris during the past 20 years. $N$ Engl J Med 1995; 332: 281-5

28 Adamopoulos DA, Pappa A, Nicopoulou S et al. Seminal volume and total sperm number trends in men attending subfertility clinics in the greater Athens area during the period 1977-33. Hum Reprod 1996; 11: 1936-41

29 Irvine SE, Cawood E, Richardson D, MacDonald E, Aitken J. Evidence of deteriorating semen quality in the United Kingdom: birth cohort study in 577 men in Scotland over 11 years. Br Med J 1996; 312: 467-71

30 Menchini-Fabris F, Rossi P, Palego P, Simi S, Turchi P. Declining sperm counts in Italy during the past 20 years. Andrologia 1996; 28: 304

31 De Mouzon J. Declining sperm count. Br Med J 1996; 313: 43
32 Suominen J, Vierula M. Semen quality of Finnish men. Br Med J 1993; 306: 1579

33 Ginsburg J, Prelevic G, Hardiman P. Residence in the London area and sperm density. Lancet 1994; 343: 230

34 Bujan L, Mansat A, Pontonnier F, Mieusset R. Time series analysis of sperm concentration in fertile men in Toulouse, France between 1977 and 1992. Br Med J 1996; 312: 471-2

35 Waeleghem K, de Clercq NL, Vermeulen LF, Schoonjans FF, Comhaire F. Deterioration of sperm quality in young healthy Belgian men. Human Reprod 1996; 11: 325-9

36 Vierula M, Niemi M, Keiski A, Saaranen M, Saarikoski S, Suominen J. High and unchanged sperm counts of Finnish men. Int J Androl 1996; 19: 11-7

37 Handelsman DJ. Sperm output of healthy men in Australia: magnitude of bias due to self-selected volunteers. Human Reprod 1997; 1: 2701-5

38 Berling S, Wölner-Hanssen P. No evidence of deteriorating semen quality among men in infertile relationships during the last decade: a study of males from Southern Sweden. Human Reprod 1997; 12: 1002-5

39 Fisch H, Goluboff ET, Olson JH, Feldshuh J, Broder SJ, Barad DH. Semen analyses in 1,283 men from the United States over a 25-year period: no decline in quality. Fertil Steril 1996; 65: 1009-14

40 Paulsen CA, Berman NG, Wang C. Data from men in greater Seattle area reveals no downward trend in semen quality. Further evidence that deterioration of semen quality is not geographically uniform. Fertil Steril 1996; 65: 1015-20

41 Weber RFA, Vreeburg JTM. Bias and confounding in studies of sperm counts. Pure Appl Chem 1998; 70: 1703-11

42 Mieusset R, Bujan L. Testicular heating and its possible contributions to male infertility: a review. Int J Androl 1995; 18: 169-84

43 Fisch H, Goluboff ET. Geographic variations in sperm counts. A potential cause of bias in studies of semen quality. Fertil Steril 1996; 65: 1044-6

44 Auger J, Jouannet P. Evidence for regional differences of semen quality among fertile French men. Human Reprod 1997; 12: 740-5

45 Jørgensen N, Andersen A-G, Eustache F et al. Regional differences in semen quality in Europe. Human Reprod 2001; 16: $1012-119$

\section{Authors}

R.F.A. Weber, MD, PhD, Internist-endocrinologist/EAA andrologist.

F.H. Pierik, PhD, Health Scientist.

G.R. Dohle, MD, PhD, Urologist/EAA andrologist.

A. Burdorf, MSc, PhD, Epidemiologist, Occupational Hygienist. Correspondence: R.F.A. Weber, Department of Andrology, Erasmus University Medical Centre Rotterdam, Dr Molewaterplein 40, 3015 GD Rotterdam, the Netherlands. email: weber@inw3.azr.nl

Abbreviations: MIS, Müllerian inhibiting substance; TDS, testicular dysgenesis syndrome; Insl 3, insulin-like factor 3; 17-EE, $17 \alpha$-ethinyl oestradiol. 